\title{
NATURE-BASED WATER TREATMENT SOLUTIONS AND THEIR SUCCESSFUL IMPLEMENTATION IN KATHMANDU VALLEY, NEPAL
}

\author{
ZUZANA BOUKALOVÁ ${ }^{1,2}$, JAN TĚŠITEL ${ }^{2,3}$ \& BINOD DAS GURUNG ${ }^{2,4}$ \\ ${ }^{1}$ VODNÍ ZDROJE, a. s., Czech Republic \\ ${ }^{2}$ METCENAS o. p. s., Czech Republic \\ ${ }^{3}$ AMBIS a. s., Czech Republic \\ ${ }^{4}$ Czech University of Life Sciences, Czech Republic
}

\begin{abstract}
Surface and groundwater in cities and downstream urban areas may suffer from serious pollution from point and diffuse sources from upstream and in-catchment, which might have a negative impact on the ecology, quality of life and land values of the city. Enhanced nature-based treatment solutions (such as constructed wetlands) have the potential to remove pollutants from the water (e.g. storm water, urban run-off, river water and wastewater) that will lead to improved water quality and water use efficiency. Such natural treatment measures, when well organised and integrated into the overall urban planning and design, can also contribute to climate adaptation by reducing drought/flood risk and constitute attractive components of the urban landscape. The constructed wetlands are a strategic nature-based technology for Nepal, where discharge of untreated wastewater into rivers, lakes or any other water body is a common practice. Constructed wetlands are highly efficient in removing organic, insoluble substances and some pesticides, and their construction and operation are both simple and cost-effective. However, the main conditions of the successful implementation of the constructed wetlands in Nepal (and the other developing countries) should be clearly stated. Legislation and standards in Nepal are weak and, therefore, wastewater treatment is not a priority for city governments and private institutions. Despite constructed wetlands being a low-cost technology, it might be difficult to convince people to pay for their wastewater treatment. The key issue is "who" takes the responsibility for their maintenance and how this responsibility is defined and granted. Our paper discusses the best and worst practices in the Kathmandu Valley and the conditions that could influence the successful implementation of the nature-based treatment solutions in developing countries more generally.
\end{abstract}

Keywords: water management, nature-based water treatment solutions, constructed wetlands, pollution control, land management, communities, Nepal.

\section{INTRODUCTION}

Constructed wetlands are highly efficient in removing organic and insoluble substances and could be as well used for the degradation of pesticides, but this efficiency is highly variable for different substances. The greatest efficiency of wetlands has been demonstrated for organo-chlorinated pesticides, organo phosphates, Pyretroid and Strobin, on the contrary, the lowest for Triazins and uric acid derivatives. Pesticide degradation generally increases with the increasing value of the adsorption coefficient, but this dependence is not linear and too strong [1].

More, the construction and operation of the constructed wetlands are both simple and costeffective, with low energy consumption (if any).

In Nepal, the most suitable location for the operation of constructed wetlands is the Kathmandu Valley where population is concentrated in three big cities (Kathmandu, Lalitpur and Bhaktapur Districts). At the same time, none of the five wastewater treatment plants, constructed in the past in the Kathmandu Valley is fully functional as of 2019 (an activated sludge plant at Guheshwori, non-aerated lagoons at Kodku and Dhobighat, and aerated lagoons at Sallaghari and Hanumanghat) [2]. 
Management of wastewater - particularly from households - is becoming an increasing problem in the Kathmandu Valley due to the increasing migration to cities [3]. Kathmandu Valley is characterized by high population growth (estimated to be $6.6 \%$ per annum) and high population density (estimated at more than 2,500 persons per $\mathrm{km}^{2}$ ). The total population of Kathmandu Valley was estimated at 2.51 million in 2011 (CBS, census 2011) and will probably reach 3.26 million by 2021 .

The existing wastewater network has not been maintained or expanded to serve the spreading urban areas and increased population. This has resulted in untreated sewage being discharged directly into local watercourses. The rivers have become open sewers presenting severe public health risks, in particular to the urban poor. Legislation and standards in Nepal are weak and therefore wastewater treatment is not a priority for city governments, private institutions and industries. However, the communities care.

In 2013, a comprehensive solution to the situation was proposed: The Kathmandu Valley Wastewater Management Project (KVWMP) of the government of Nepal, which, however, was still not completed in 2019 (in December 2019, testing of its part, the newly reconstructed Guheshwori Wastewater Treatment Plant, was launched). This project is aimed at improving wastewater services in Kathmandu Valley through extensive investment in rehabilitating and expanding the sewerage networks; modernizing and constructing wastewater treatment plants (WWTPs); and supporting operational and financial improvements and capacity building. The work includes the rehabilitation and construction of new WWTP at Kodku (Patan), Sallaghari (Bhaktapur), Dhobighat (Kathmandu) and Guyesheshowri (Kathmandu). All WWTPs designed under this project will be rehabilitated or constructed in the land area owned by government [4]. This should ensure their proper operation, continuous specialist's supervision as well as sufficient electric power supply.

In the Kathmandu Valley, constructed wetlands could then support the wastewater management out of reach of the WWTPs and provide additional wastewater treatment for a number of households, especially in areas, where water retention at landscape is needed, groundwater level is continuously declining and local hydrogeological situation is favourable for the water infiltration.

The idea of our research in Kathmandu Valley and as well of this paper is to review the recent situation of the constructed wetlands in the area. Next, find the circumstances, that are influencing wetlands functioning and define the important issues for their successful maintenance. The part of our research work is as well the construction of the pilot wetland, which would serve as the good example in the area. Via this pilot plant we would like to demonstrate how the wastewater management problems could be solved by the nature-based solution favourable for both, the local community/owner of the area and the environment.

An ideal area for this pilot plant (constructed wetlands) here is e. g. Lalitpur where the water supply situation has been critical since 2006, when continuous decline in groundwater levels began due to a combination of causes such as large engineering operations, collapse of the local water supply network, increasing migration as well as excessive groundwater abstraction [5]. Other suitable areas include smaller community districts on the city edge outside the densely built up city areas, such as Dhulikhel, Sano Khokana, or Tokha.

\section{WORK METHODOLOGY}

Constructed wetlands is a biological wastewater treatment technology designed to mimic processes found in natural wetland ecosystems. These systems use wetland plants, soils and their associated micro-organisms to remove contaminants from wastewater [6].

Categorized by flow pattern, we divide constructed wetlands into free water surface wetlands and subsurface flow wetlands. Both these types of constructed wetlands utilize 
emergent aquatic vegetation. In the free water surface wetlands, water flows at a shallow depth horizontally over media which support the roots of the vegetation. The flow is above the substrate which makes the top layer of flow aerobic and the lower layers can be anaerobic. In addition to treating wastewater, free water surface wetlands can be aesthetically pleasing as they look like natural marshes and may provide wildlife habitat.

Subsurface flow wetlands are made up of pretty much the same components as the free water surface wetlands. The difference is that the flow of wastewater is designed to remain below the top of the media in the subsurface flow wetlands. Because the flow of wastewater is in the subsurface, odour and pest problems are minimized. Wastewater has also more contact with the porous media because the flow runs through the media and not over it. This can make the subsurface flow wetlands smaller in size compared to a free water surface wetlands treating the same amount of wastewater that is important for city areas.

Free water surface wetlands can become potential mosquito breeding grounds if not properly designed. Subsurface flow wetlands are therefore preferred in tropical and subtropical climates and are as well the best solution for Nepal, Kathmandu Valley, where the area available for their construction is rather limited.

There are two main directions of flow in the subsurface flow wetlands; horizontal flow and vertical flow, both has certain advantages and limitations. By combining them, we get a hybrid system that complements each other [7]. In horizontal flow wetlands, the wastewater flows from the inlet in the bed to the outlet of the bed in a horizontal path. As the wastewater moves slowly through the porous substrate, it encounters anaerobic, aerobic and anoxic zones. Organic pollutants are effectively removed in horizontal flow wetlands by microbiological degradation and by physical and chemical processes. The removal of nutrients is limited there due to lack of oxygen in the bed. Nitrates are however removed.

In vertical flow wetlands, the wastewater is fed intermittently over the bed so that it floods the top of the bed. The wastewater then moves vertically through the substrate before it is collected in drainage pipes at the bottom. Between loadings the bed is drained free of wastewater which allows air to fill the bed again. The next loading traps the air inside the bed and leads to good transfer of oxygen which allows nitrification.

Vertical flow wetlands removes organic matter and pathogens efficiently and takes up less space than a horizontal flow wetlands. Horizontal flow wetlands are better when it comes to removal of solids and as well they remove organic matter efficiently, but it takes up more space. Vertical flow wetlands have better oxygen transfer, hence the ability to nitrify, but can become clogged if the selection of media is wrong.

For Nepal, the horizontal flow constructed wetlands are easier to be maintained successfully, however the hybrid system could be better in the developed areas in the cities, with the limited space; for example for the private houses or schools.

Even though constructed wetlands have proven effective for treating different kinds of wastewater, there are still some challenges in the promotion of them. Despite constructed wetlands being a low-cost technology it might be difficult to convince people to take a basic care about the constructed wetlands and pay to treat their wastewater rather than just discharging it into the river (as there is no legislation and penalties to "convince" them). Gravel, sand and reeds might not be locally available for construction. Next, the management of the constructed wetlands is not organised by some communities in a satisfactory way, even the constructed wetland does not require much operation and maintenance. However it is important, that the system is treated efficiently and the constructed wetland is supervised by the responsible well-informed person from time to time.

In the literature and on available websites, about 60 constructed wetlands in the Kathmandu Valley and its immediate surroundings are marked. In the current situation of 
poor wastewater management, these wetlands are considered to be the most effective way of household wastewater treatment in this area.

During a field investigation directly in the Kathmandu Valley in September 2019, we were able to confirm only 23 of the documented constructed wetlands, the majority of which were described on the Environment and Public Health Organization (ENPHO) website (http://demo.crossovernepal.com/NP00100/?iec=factsheets).

In the field survey, we found that out of these 23 constructed wetlands, as few as seven constructed wetlands were fully functional and in good state. Three out of 23 constructed wetlands work only partially and 10 constructed wetlands have ceased to exist or have been destroyed by floods or landslides. In the case of three constructed wetlands, personal access to determine their situation was denied to us.

Considering the entities operating these 23 constructed wetlands, they can be divided in the following manner:

- Constructed wetlands on school premises: 1 functional, 1 partially functional, 2 not functional, 1 not accessible

- Constructed wetlands for bigger communities (over 20 families): 1 functional, 1 partially functional, 2 not functional, 1 not accessible

- Constructed wetlands for institutions:

$\checkmark$ Research institutions and offices: 2 functional, 4 not functional

$\checkmark$ Hospitals: 1 functional, 1 not functional (Figs 1 and 2: Sushma Koirala hospital constructed wetlands - the success story)

$\checkmark$ Monasteries: 1 not functional

$\checkmark$ Industrial establishment: 1 functional

- Constructed wetlands for private houses: 1 functional (other 2 functional, by hearsay), 1 partially functional, 1 not accessible.

The field research, that followed the literature review of the construction wetlands situation in the Kathmandu Valley, was organised via visits of the constructed wetlands and discussion with the owners/maintenance staff / community in the form of semi-standardised interviews (see the Fig. 2).

We focused especially on the socio-economic context of the constructed wetland implementation in Nepal, which, in absence of an effective state regulatory framework, is the most important factor for a successful implementation in situ. The questions of the interviews were related to:

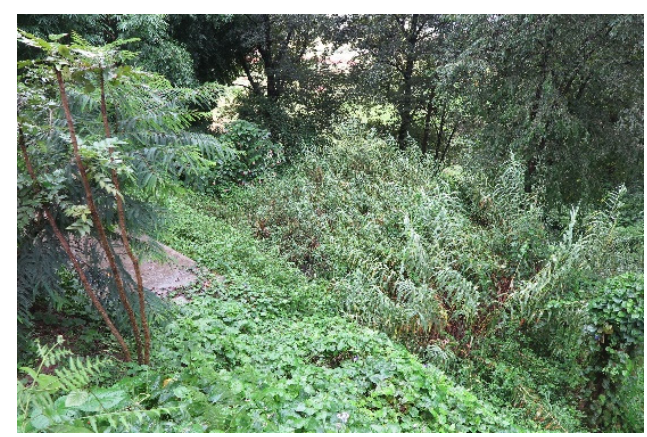

Figure 1: Sushma Koirala hospital - the well-functioning, constructed wetland. 


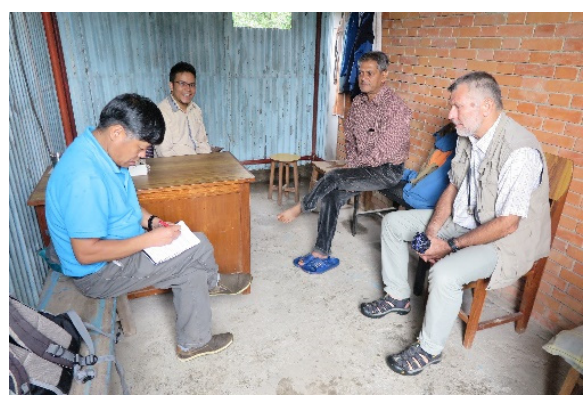

Figure 2: Interview with the person taking care of the Sushma Koirala constructed wetland.

- Ownership of the constructed wetland (who "owns it" - for whom it was constructed, why and how the particular community/settlement/household was identified for the constructed wetlands).

- Socio economic description of the community/settlement/household (in terms of caste, ethnic group, economic class), length of stay at the spot (permanent - immigrants), number of members/users.

- Involved stakeholders and financial source: who initiated wetland construction and why, what financial source were used and why these particular ones, etc.

- Why this particular technology of wastewater treatment was implemented? Was it promoted or supported by some financial schemes (national or international) or legislation?

- Present situation, technical management aspects, typology of the constructed wetlands, and the reasons for functioning, semi-functioning or not functioning of the constructed wetlands.

The results of our questionnaire campaign showed that the public awareness regarding constructed wetlands technology is the major challenge for this technology development. Based on our in situ investigation it is clear, that it is often difficult to involve community, institutions, and organizations for the installation of technology. The consideration of system as a low maintenance technology led to carelessness during operation and maintenance [8]. Further, wastewater treatment is not the priority for government, communities, and some institutions, due to the lack of strong legislation and standards [9]. (The detail evaluation of the interviews, however, will be the subject of the following paper, after the extensive campaign in the year 2020).

We were wondering why some constructed wetlands worked well and other had been neglected. The most important factor seemed to be the person/position of the operator, their awareness and level of involvement in the project. For this reason, we decided to place the pilot constructed wetland - which should be monitored from the beginning, to serve as a good practice example for potential technology transfer as well as training activities - either on school premises or on the premises of a big governmental or community institution.

For the implementation of the pilot constructed wetland, two potential sites were initially suggested - (a) NOBS schoolyard in Kathmandu, and (b) premises of the municipal office of Dhapakhel, one of the administrative units of the city of Lalitpur. The final decision was made when the Chairperson of Ward of Dhapakhel showed great interest in the collaboration and the project was also supported by the headmaster of the New Sumnima English School in Chakupat. This combination proved ideal for us. 


\section{PILOT PLANT}

Unlike European households, Nepalese households produce little sewage. For this reason, horizontal system with subsurface flow was chosen for the project BIORESET model constructed wetland in Lalitpur. For the location of the constructed wetland, municipal office (Ward Office) of the Lalitpur Sub-metropolitan City, which is a state administrative authority, was chosen. This municipal office in Dhaphakhel suffers from (both sanitary and drinking) water supply shortage. Thus, the Chairperson of Ward welcomed the possibility of reusing the treated wastewater from toilets, washrooms and the kitchen (Fig. 3). At the same time, he suggested combining the wastewater treatment plant with a rainwater harvesting system, to assure enough water to maintain the wetland, which as he promised, was financed from the municipal budget. The Chairperson of Ward is a very active man. Among other things, he organises public health and environment protection promotion campaigns for the representatives of other municipal offices in Lalitpur. Thus, he will use the constructed wetland to raise awareness among his colleagues and, moreover, as a "learning aid" for the teachers and students of the New Sumnima School.

We placed the constructed wetland pilot plant on the premises of the municipal office and projected that a neighbouring police station is also connected to it; thus, the constructed wetland treats wastewater from the facilities of the municipal office, police station as well as a community training centre and it is designed for 22 to 25 users. The construction itself was carried out in September 2019 using funds provided by the company VODNÍ ZDROJE, a.s., the organisation AMBIS, the Ministry of Education, Youth and Sports of the Czech Republic, and the municipal office of Dhapakel.

The constructed wetland was located in the lowest part of the municipal office yard directly in front of the training centre building based on the agreement with the Chairperson of Ward, his team and the representatives of a local construction company.

The basic principle of the implemented system is horizontal flow of wastewater through a permeable substrate planted with wetland plants - calamus vegetation (Fig. 4). The sub-tropical climatic condition of urban areas of Nepal stimulated better growth of rhizosphere plant which led to better biological activity in soil for constructed wetlands performance [10], however in Dhapakel, we used recommended local plants (calamus).

The wetland is preceded by a septic tank where mechanical pre-treatment of sludge takes place. The filter bed of the wetland is $8 \mathrm{~m}$ long, $2 \mathrm{~m}$ wide and $1.5 \mathrm{~m}$ deep (Fig. 5), and is reinforced with a liner that was made by mixing a local material, i.e., clayey soil, with cement. This lining was thoroughly compacted both on the sides and the bottom of the filter bed. Then, filter material - gravel and, subsequently, sand - was placed into the filter bed. The treated water from the wetland is conveyed by gravity to a well $3 \mathrm{~m}$ deep, located at a distance of approx. $2 \mathrm{~m}$ (Fig. 6). This newly constructed well is used both for storage of sanitary water-treated water as well as rainwater, and has an infiltration purpose: through the bottom, the water infiltrates into the shallow aquifer, recharging the local drinking water sources.

The whole plant consisting of a constructed wetland, rainwater harvesting system and storage well was officially handed over for use to the Dhapakhel municipality in the presence of the headmaster of the New Sumnima School and the representatives of organisations involved in the project E! 12219 BIORESET: The use of controlled bioremediation for removal of specific types of contaminants.

The municipality Chairperson of Ward took over the constructed wetland appointing a person responsible for its maintenance and continuous inspection of the filter bed conditions, the biological components as well as the quality of water leaving the wetland. 


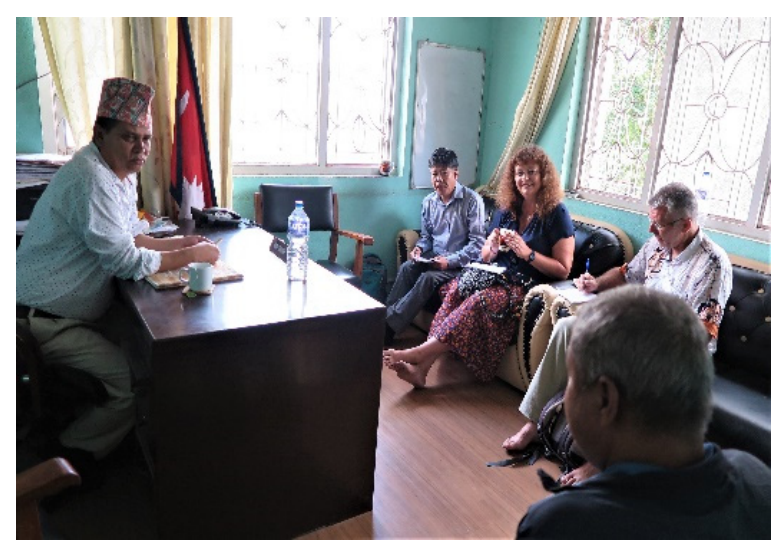

Figure 3: The Chairperson of the Ward welcomed the possibility of constructed wetlands implementation.

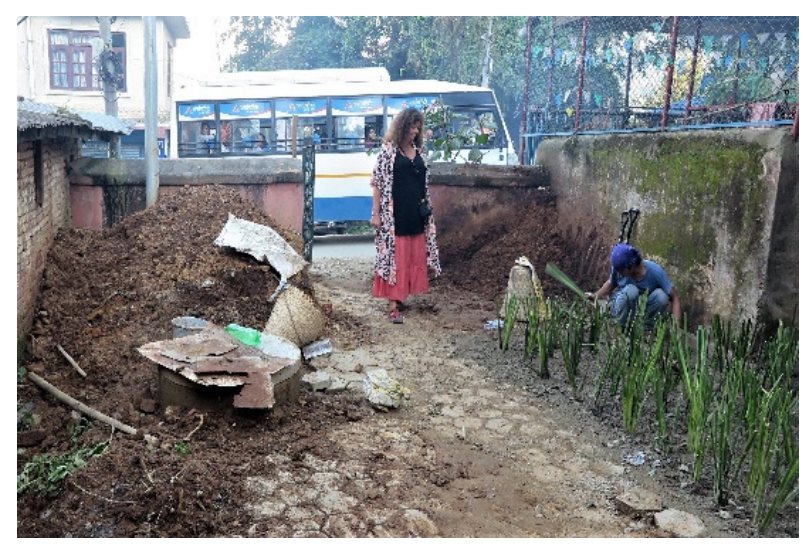

Figure 4: Finalisation of the constructed wetland's site.

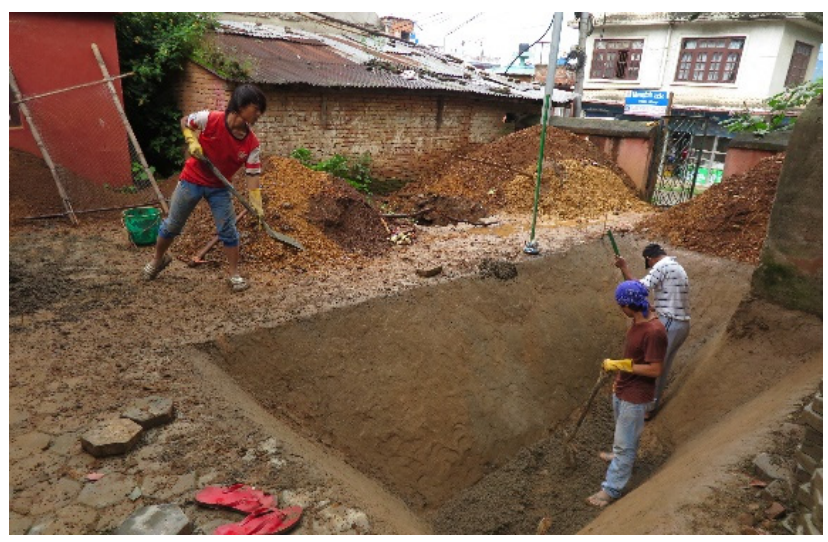

Figure 5: Building of the constructed wetlands in Dhaphakhel, Lalitpur. 


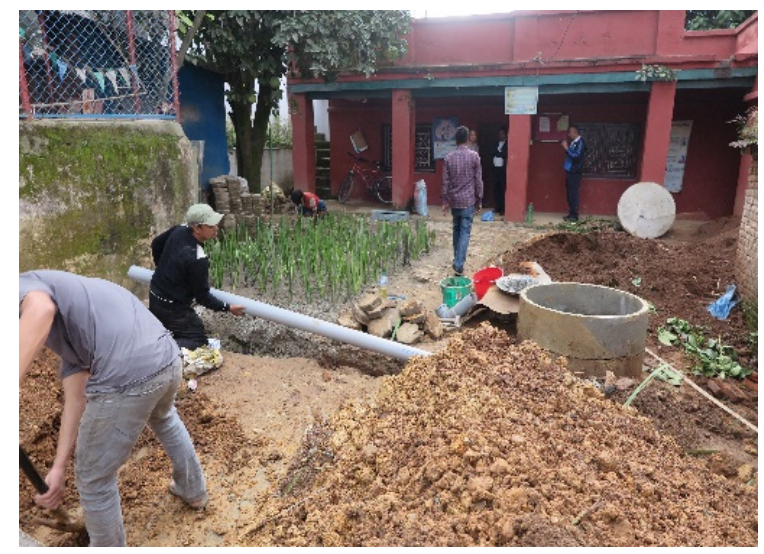

Figure 6: Building of the accumulation well.

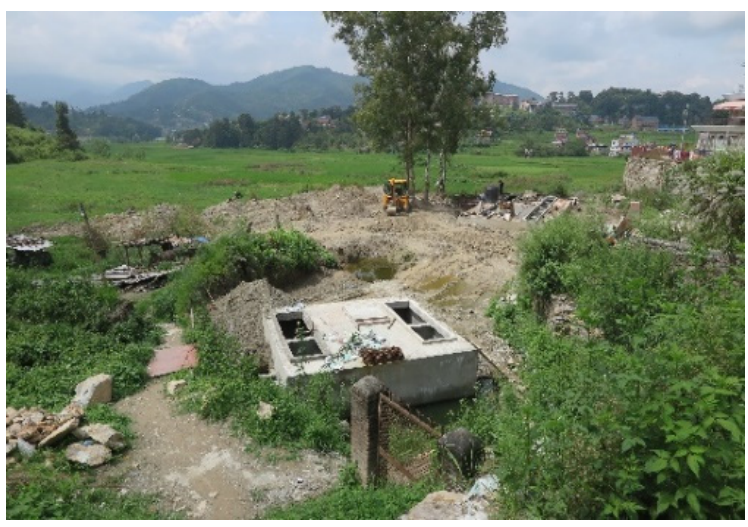

Figure 7: Dhulikhel hospital - building of the new constructed wetlands.

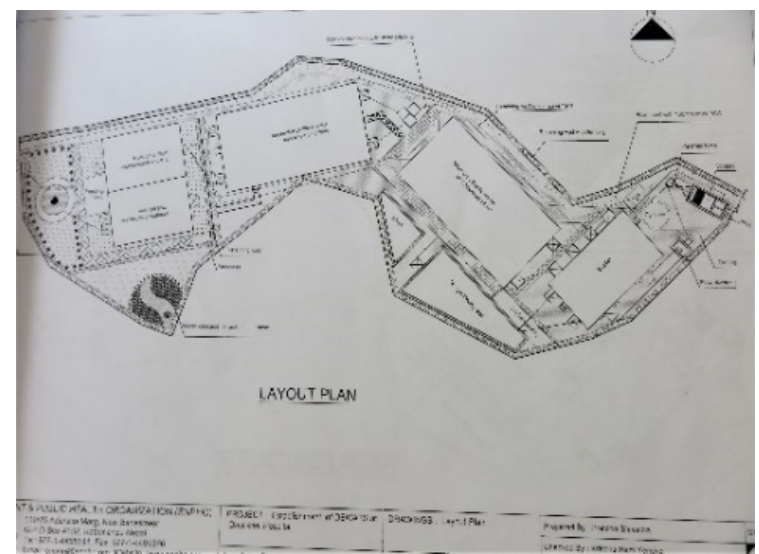

Figure 8: The plan for the new constructed wetlands at Dhulikhel hospital. 


\section{THE SPECIAL CASE: HOSPITALS}

The implementation of constructed wetlands in private hospitals in the Kathmandu Valley is relatively successful. We would like to mention two success stories - Dulikhel hospital and Sushma Koirala Memorial Plastic and Reconstructive Surgery Hospital best practices.

In suitable hydrogeological and geographical conditions, private hospitals, in most cases also supported by foreign subsidies, are suitable for the implementation of constructed wetlands, as they are monitored both by the state and the donors as well as local communities as far as the quality of the released water and management of toxic substances are concerned; second, they have enough space for the installation of constructed wetlands and personnel to systematically deal with the operation of the constructed wetlands in the long run. For instance, in Sushma Koirala Memorial Plastic and Reconstructive Surgery Hospital located in Sankhu (where constructed wetlands were implemented in 2002 and enlarged and cleaned over time), the operation and maintenance of the plant is managed by the well - trained permanent hospital engineering staff and routine maintenance is included within the overall hospital maintenance plan.

The Dulikhel hospital (a Kathmandu University Teaching Hospital located in Dhulikhel Municipality, Kavrepalanchok District Nepal) had built the constructed wetlands in 1997 as a medium sized system consisting of three phase treatment (Anaerobic Baffle Reactor, Horizontal Wetland, Vertical Wetland) with two systems operating in parallel and a sludge drying bed to complete the wastewater treatment process. It had been renovated in 2008 (targeting 250 patients and staff of the hospital). The new reconstruction started in 2019 after serious damages by floods in the June 2019, because for the hospital, it is challenging to manage wastewater coming from the hospital and eliminate the organic pollutants from the water, which is used for the irrigation of agricultural fields in the vicinity (Figs 7 and 8).

However, until the time, nobody has raised the issue of inorganic (chemical and pharmaceuticals) pollution in the water coming from the hospital; there is no regular monitoring of these substances. The community people are happy to use water from outlet for irrigation purpose without the monitoring of the chemical parameters of the outlet water though twice in a year biological parameters are usually monitored.

The Dhulikhel hospital (that is the first subject who organised constructed wetlands in Nepal [11]. is promoting the nature-based technology approach because of following reasons: (1) they have enough land for constructed wetlands building (what is not a case in the more urbanised area of Kathmandu Valley), (2) there is suitable topography which doesn't require additional energy to run the system of constructed wetlands, (3) to promote locally available resources, (4) to show others the constructed wetland and their maintenance as a model, and (5) as this solution is economic in long term though it was comparatively quite expensive at the beginning (but there was the financial support by the international donor managed by ENPHO for the start-up activities).

Similar constructed wetlands can be replicated in other areas, not only for the hospitals, but as well for communities, thanks this "success story," as it has good network and information flow because of (a) many patients and their families/visitors can see and learn, (b) students are passing the training in the hospitals and could bring the constructed wetlands experiences to their home areas, (c) the Rural health camp is organised in the area and both, the Public health department and the Community development department can use the constructed wetlands case as teaching tool/subject and finally (d) many organised visitors (around 20 groups in a year) visit and see the system.

The horizontal flow constructed wetlands have long been used primarily for treatment of municipal or domestic wastewaters. Nowadays, they focus not only on common pollutants 
but also on special parameters available in the waters from agriculture or hospitals (such as pharmaceuticals, endocrine disruptive chemicals or linear alkylbenzensulfonates) [1].

However, the question remains whether the use of constructed wetlands for treating wastewater from hospitals in Third countries (that means as well as Nepal) is safe, because the management of toxic materials and residues is not satisfactorily dealt with within the wastewater management schemes. The quality of the water flowing into and released from the constructed wetlands is not regularly monitored for all the necessary parameters (such as various pharmaceuticals that can get into the water with the patients' urine).

Therefore, it is very likely that the water flowing out of the constructed wetlands may contain some Emerging Contaminants (synthetic organic chemicals that are detected in the natural environments), which are not degradable in the natural rock formations and can contaminate surface or ground water, or water used for irrigation of farmland.

For these reasons, we decided to establish a model constructed wetland pilot plant in the Kathmandu Valley in other environment than that of a hospital.

\section{CONCLUSION}

Due to the failure of the large treatment plants, small and decentralized treatment systems such as constructed wetlands are of high importance in Kathmandu Valley till now (the year 2019).

As discussed above, the most suitable environment for the constructed wetland pilot implementation has been identified in areas which have funds and staff for their operation, enough space as well as enough wastewater polluted with organic contaminants, and where the toxic or industrial pollutants are not expected to be presented in the wastewater.

At the same time, the operator of the constructed wetland (being also the manager of the premises where it is located) is interested in the environment and the abidance by the environment protection rules supported by his religious and social convictions as well as economic interests is a matter of prestige for him.

In private schools, for example, the presence of a constructed wetland may enhance the school's reputation, which will reflect in the students' increased interest in studying there and, at the same time, will ensure appropriate education of the students in the area of preserving a high-quality environment for a life (as an example, a very successful constructed wetland and rainwater harvesting system in the Satya Sai Sikshya Sadan school can be mentioned - see the Fig. 9). In another highly suitable type of site - municipal premises (such as Ward Offices) where the necessary funding for the operation of the constructed wetland can be procured more easily - the constructed wetland practice can be spread among other Chairpersons as well as communities living in the immediate vicinity thanks to a manager that is open to innovations.

Such communities, led by an enlightened leader who is in contact with "his" Chairperson of Ward, can then be effectively trained as to how to properly handle constructed wetlands, manage them and ensure their operation; via the municipality and its connection to appropriate national or international organisations, they can even obtain the necessary "initiating" means to launch the application of a constructed wetland in their own locality. Another suitable type of site, which is specific for Nepal and where a significant development in alternative tourism is now taking place, includes a constructed wetland implementation in tourist resorts or centres for spiritual practice and yoga for foreign clients, where it is desirable to demonstrate a connection to nature (as an example of partial success, the Namo Budha Resort can be mentioned - see Fig. 10). 


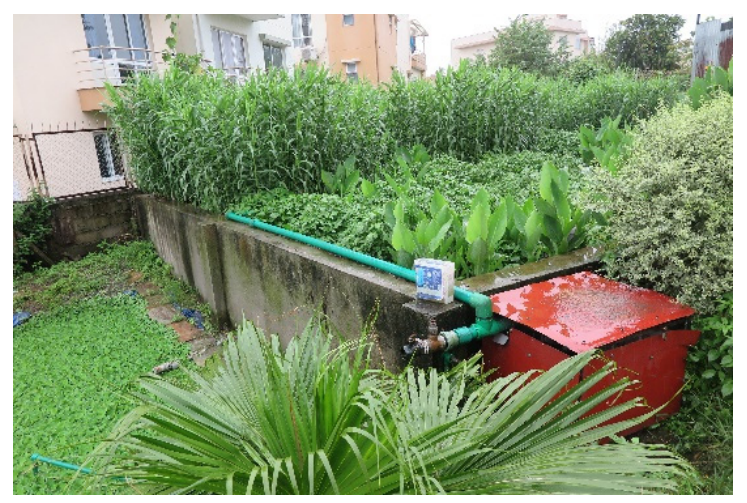

Figure 9: Constructed wetland in the Satya Sai Sikshya Sadan school.

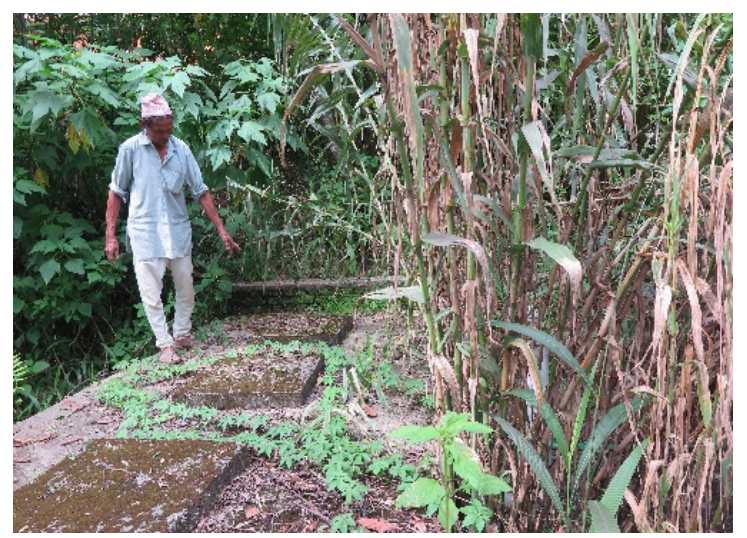

Figure 10: Semi functioning constructed wetland in the Namo Budha Resort.

Under the BIORESET project, we finally decided to establish a model constructed wetland on municipal land (Ward Office of Lalitpur Sub-metropolitan City), where sufficient amounts of wastewater as well as suitable space and a responsible person to oversee the operation of the constructed wetlands was ensured [12]. Strategical issue was as well to involve not only Ward Office of local government and police station to the activities, but as well the headmaster of the New Sumnima English School in Chakupat, living in the area and involved in the Ward Management Committee of the Municipality. The selection of the governmental place for the constructed wetlands building and operation and the educative and training potential have the long term positive impacts on the knowledge transfer and replication of the constructed wetlands in other areas/community places.

\section{ACKNOWLEDGEMENTS}

This paper was developed thanks to the EUREKA project E! 12219 BIORESET, co-financed by the Ministry of Education, Young and Sports, Czech Republic (50\%) and organizations VODNÍ ZDROJE a.s. and AMBIS, a.s., as well thanks to the INTER-COST project "Natural Based Solutions for water management in cities", financed by the Ministry of Education, Young and Sports, Czech Republic. 


\section{REFERENCES}

[1] Vymazal, J., The use constructed wetlands with horizontal sub-surface flow for various types of wastewater. Ecological Engineering, 35, pp. 1-17, 2009.

[2] Green, H., Poh, S.-Ch. \& Richards, A., Wastewater treatment in Kathmandu, Nepal. Massachusetts Institute of Technology, 2003. http://web.mit.edu/watsan/Docs/ Student\%20Reports/Nepal/NepalGroupReport2003-Wastewater.pdf.

[3] Mishra, B.K. et al., Assessment of Bagmati river pollution in Kathmandu Valley: Scenario-based modelling and analysis for sustainable urban development. Sustainability Water Quality and Ecology, 9-10, pp. 67-77, 2017. http://dx.doi.org/10.1016/j.swaqe.2017.06.001.

[4] NEP, Kathmandu Valley Wastewater Management Project (2018): Kathmandu Upatyaka Khanepani Limited Project Implementation Directorate Anamnagar, Kathmandu. http://www.kuklpid.org.np/kukl/.

[5] Boukalova, Z., Těšitel, J., Hrkal, Z. \& Kahuda, D., Artificial infiltration as integrated water resources management tool. Water Pollution XII, Water Pollution Conference, The Algarve, Portugal, pp. 201-210, 2014.

[6] Tuladhar, B., Shrestha, P. \& Shrestha, R., In Urban Sanitation, Decentralised Wastewater Management Using Constructed Wetlands, ENPHO, pp. 86-94, 2008.

[7] Yalcuk, A. \& Ugurlu, A., Comparison of horizontal and vertical constructed wetland systems for landfill leachate treatment. Bioresource Technology, 100, pp. 2521-2526, 2009. www.elsevier.com/locate/biortech.

[8] Shrestha, R.R., Application of constructed wetlands for wastewater treatment in Nepal. Dissertation, University of Agricultural Sciences, 1999.

[9] Pudasaini, K., Performance of wastewater treatment plants (BASP and SWTP) in Kathmandu valley: Case study of Bagmati area sewerage treatment plant (BASP) and Sunga wastewater treatment plant (SWTP), Master's thesis, Institute of Water Education, 2008.

[10] Murthy,V. K., Khanal, S.N., Majumder, A.K., Weiss, A., Shrestha, D. \& Maharjan, S., Assessment of performance characteristics of some constructed wetlands in Nepal, Kalmar Eco-Tech '07 Kalmar Sweden, 26-28 Nov., 2007.

[11] Environment and Public Health Organization. www.enpho.org.

[12] Boukalova, Z., Těšitel, J. \& Gurung, D.B., Constructed wetlands and their implementation on private and public land in Kathmandu valley, Nepal. WIT Transactions on Ecology and the Environment, vol. 229, WIT Press: Southampton and Boston, pp. 1-8, 2019. 